\title{
A Modified Hybrid III 6-Year-Old Dummy Head Model for Lateral Impact Assessment
}

\author{
I. A. Rafukka, ${ }^{1,2}$ B. B. Sahari, ${ }^{1}$ A. A. Nuraini, ${ }^{1}$ and A. Manohar ${ }^{3}$ \\ ${ }^{1}$ Department of Mechanical and Manufacturing Engineering, Faculty of Engineering, Universiti Putra Malaysia (UPM), \\ 43400 Serdang, Selangor, Malaysia \\ ${ }^{2}$ Department of Mechanical Engineering, Bayero University, PMB 3011, Kano, Nigeria \\ ${ }^{3}$ Department of Orthopaedic Surgery, Faculty of Medicine and Health Sciences, Universiti Putra Malaysia (UPM), \\ 43400 Serdang, Selangor, Malaysia \\ Correspondence should be addressed to I. A. Rafukka; ibrahimrafukka@yahoo.com
}

Received 29 July 2015; Revised 24 December 2015; Accepted 24 December 2015

Academic Editor: Radu Danescu

Copyright (C) 2016 I. A. Rafukka et al. This is an open access article distributed under the Creative Commons Attribution License, which permits unrestricted use, distribution, and reproduction in any medium, provided the original work is properly cited.

\begin{abstract}
Hybrid III six-year-old (6YO) child dummy head model was developed and validated for frontal impact assessment according to the specifications contained in Code of Federal Regulations, Title 49, Part 572.122, Subpart N by Livermore Software Technology Corporation (LSTC). This work is aimed at improving biofidelity of the head for frontal impact and also extending its application to lateral impact assessment by modifying the head skin viscoelastic properties and validating the head response using the scaled nineyear-old (9YO) child cadaver head response recently published in the literature. The modified head model was validated for two drop heights for frontal, right, and left parietal impact locations. Peak resultant acceleration of the modified head model appeared to have good correlation with scaled 9YO child cadaver head response for frontal impact on dropping from $302 \mathrm{~mm}$ height and fair correlation with $12.3 \%$ difference for $151 \mathrm{~mm}$ drop height. Right parietal peak resultant acceleration values correlate well with scaled 9YO head experimental data for $153 \mathrm{~mm}$ drop height, while fair correlation with $16.4 \%$ difference was noticed for $302 \mathrm{~mm}$ drop height. Left parietal, however, shows low biofidelity for the two drop heights as the difference in head acceleration response was within $30 \%$. The modified head model could therefore be used to estimate injuries in vehicle crash for head parietal impact locations which cannot be measured by the current hybrid III dummy head model.
\end{abstract}

\section{Introduction}

Head injury is a disaster that leads to loss of lives of vehicle occupants of all age groups. The trauma is more devastating to children who have their centre of gravity (CG) higher relative to their height which make them vulnerable to head-first fall. Head injuries are responsible for high morbidity and mortality rates of people around the world. In the United States, for example, it accounts for $30 \%$ of all injury deaths [1]. Motor vehicle crash, pedestrian collision, and falling on playgrounds are some of the causes of traumatic brain injury (TBI). Crash dummy finite element (FE) models are now used to evaluate vehicle safety systems because of their economic and technical advantages. Crash dummy FE models are developed to represent physical crash dummies; hence their responses are usually validated against the certification corridors. While these corridors were developed based on human cadaver data for adults, children models have normally been validated against scaled adult biomechanical response because of lack of child cadaver data for ethical reasons. Lack of data of children also restricts design of dummies that can measure injuries of various head locations. Recently, Loyd [2] provides head response data of children and adults that could be used as a basis in dummy head design for various impact locations. It was also shown by Loyd that children crash dummy heads need modifications to make their response similar to that of child cadaver head.

The anthropometric test device (ATD) head models are the tools used to evaluate the head response on crash by measuring the head acceleration and head injury criteria (HIC). It is incorporated to the full dummy model for crash analysis. Three-year-old Q3 dummy models are designed to 
measure parietal and forehead impacts and are validated using scaled adult head response data [3]. Hybrid III $6 \mathrm{YO}$ child dummies, however, were validated based on the Federal Code Regulations specifications which are based on scaled adult cadaver data for frontal impact only $[4,5]$. It is important therefore to improve the 6YO hybrid III dummy head FE model for side impacts because the head injury mechanism of children could be due to the contact of head with vehicle's interior on impacts or falls. Head impact location is important since differences in the skull thickness and impact kinematics can affect the impact properties [1].

Though there was no six-year-old child head cadaver response data available in the literature for the head response validation, this study utilizes recent nine-year-old child cadaver head response experimental data to validate the $6 \mathrm{YO}$ child head model for frontal and parietal locations. For frontal impact, the model was validated against scaled cadaver response of $9 \mathrm{YO}$ child which is expected to have material properties and response closer to $6 \mathrm{YO}$ child than the existing validation specifications which were based on scaled adult head response. In addition to this, the modified head model could estimate head acceleration of right and left parietals on impact. This study is aimed at modifying the head skin material properties so that the peak resultant acceleration of $6 \mathrm{YO}$ hybrid III dummy head model will be validated against scaled $6 \mathrm{YO}$ cadaver head response for three impact locations.

\section{State of the Art}

Physical and numerical ATD models are essential tools in studying injuries and evaluation of safety systems of vehicles. Child ATDs biomechanical response data are based on scaled adult data because of scarcity of paediatric postmortem human subject (PMHS) for ethical reasons. While both human and ATD paediatric heads models were studied and applied for head injury assessment in the literature, only few were validated against human data. Until recently, by Loyd [2], in the hybrid III family, only 50th percentile adult was validated against cadaveric data in frontal impact [6] but none of child ATDs was compared against human data [1].

One of the crash dummy models used is 6YO hybrid III dummy, developed by Livermore Software Technology Corporation. Lack of age matched cadaver data during the dummy design has necessitated the application of scaled biofidelity corridors based on 50th percentiles male test data to validate the biomechanical response of six-year-old child crash dummies. Validation against cadaver data was considered more realistic than using scaled corridors. Some research works have been conducted on improving the biofidelity of child numerical models. Lopez-Valdes et al. [7] compared the kinematics of hybrid III 6 YO with a child size adult PMHS in frontal sled test for the purpose of studying the differences in biomechanical response. PMHS data was scaled to $6 \mathrm{YO}$ using scaling factors and the ATD predicted displacement well but differences in torso flexion were noticed because of stiffer ATD spine. Wu et al. [8] modified the spine biofidelity of HIII $6 \mathrm{YO}$ ATD by adding joint at thoracic spine region to reduce translation characteristics of cervical and lumbar spine and validation was carried out against cadaver and volunteer test reconstructions. Hu et al. [9] modified 6YO HIII dummy abdomen design to simulate and predict submarining suffered by young children. Modified pelvis and abdomen geometry and material properties were incorporated to the dummy model and validation was done against sled test with modified physical dummy.

Side impact protection is very crucial in vehicle protection system and there is recently concern about the injuries caused by side impacts of vehicle. It was shown that side impacts are about twice as likely to cause child fatality as frontal impacts regardless of restraint status or seating position [10]. Side impact dummies are required for the assessment of the vehicle and safety systems and dummy producers are now extending their designs for side impact applications. Head, being the most injured body part, needs to be well validated to replicate real impact on human. However, there is plan initiated by LSTC to develop Q6 dummies to measure side impacts. It was obvious that LSTC encouraged parties to improve any of their dummy models [11]. PMHS data obtained recently from Loyd [2] is therefore a useful tool to modify such designs for better biofidelity in frontal location as well as to extend application of this model to side impacts. Loyd's study is useful for finite element analysis validation because of the fact that the cadaver head was isolated in free fall, unlike other studies which involve falling of full cadaver or head and neck. The purpose of this study is to modify hybrid III 6YO dummy's head properties in order to increase the biofidelity of the head for frontal impact and to extend its application for lateral impact assessment.

\section{Proposed Model/Methods}

3.1. Reference Dummy. Hybrid III 6-year-old finite element model version LST0.104.BETA is currently the latest sixyear-old child model developed by Livermore Software Technology Corporation (LSTC) in conjunction with National Crash Analysis Centre (NCAC). Its validation was based on the certification tests described in the Code of Federal Regulations, Title 49, Part 572, Subpart N. The model contains 199,102 nodes, 127,154 solid elements, 45,032 shell elements, and 142 beam elements [5]. The head assembly of this model comprises skull, skin layer, transducers, instruments mounts, and a head pivot pin. Figure 1 shows the complete dummy FE model.

3.2. Biomechanical Response Scaling. Response based scaling method has been used for biomechanical response scaling in the literature [12-16]. Scaling 9YO child biomechanical response to that of $6 \mathrm{YO}$ child is expected to yield better biofidelity because of closeness in terms of size, geometry, and material properties. Since there was no six-year-old child cadaver head data available for head validation, a nineyear-old child head biomechanical response data recently published by Loyd [2] was scaled using the method proposed by Mertz et al. [17]. The head drop test condition was considered as a spring-mass system, where head of mass $m$, 


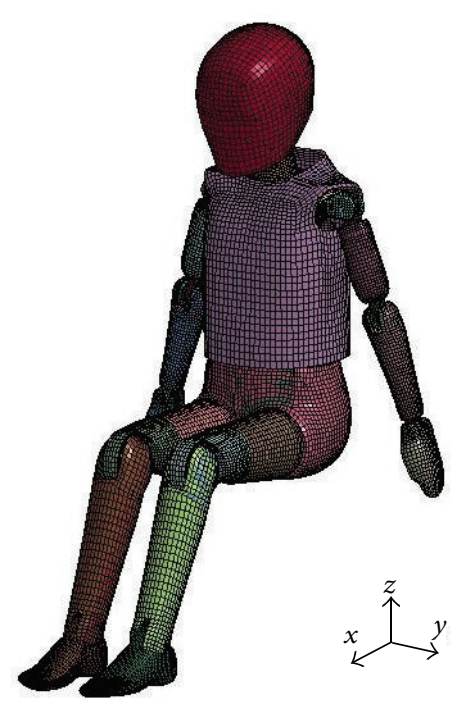

FIGURE 1: Hybrid III 6YO child dummy FE model.

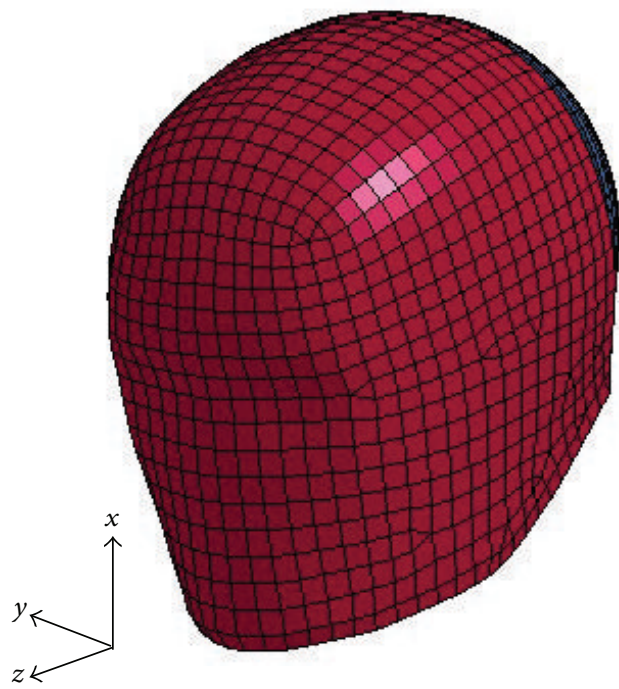

FIGURE 2: Axis orientation for scaling factors.

impacts a rigid plate with velocity $v$, so that the head stiffness $k$ can be described by the following equation:

$$
k=\frac{E A}{L},
$$

where $E$ is the bone elastic modulus, $A$ is the impact area, and $L$ is the head depth, and thus stiffness scaling factor is

$$
\lambda_{k}=\frac{\lambda_{E} \lambda_{y} \lambda_{x}}{\lambda_{z}},
$$

where $\lambda_{y}, \lambda_{x}$, and $\lambda_{z}$ are the scaling factors for the head breadth $(\mathrm{HB})$, head height $(\mathrm{HH})$, and head depth (HD), respectively (Figure 2). $\lambda_{E}$ is the elastic modulus scaling factor.

The 9YO child bone elastic modulus was obtained by interpolation from Irwin's curves that relate skull modulus as

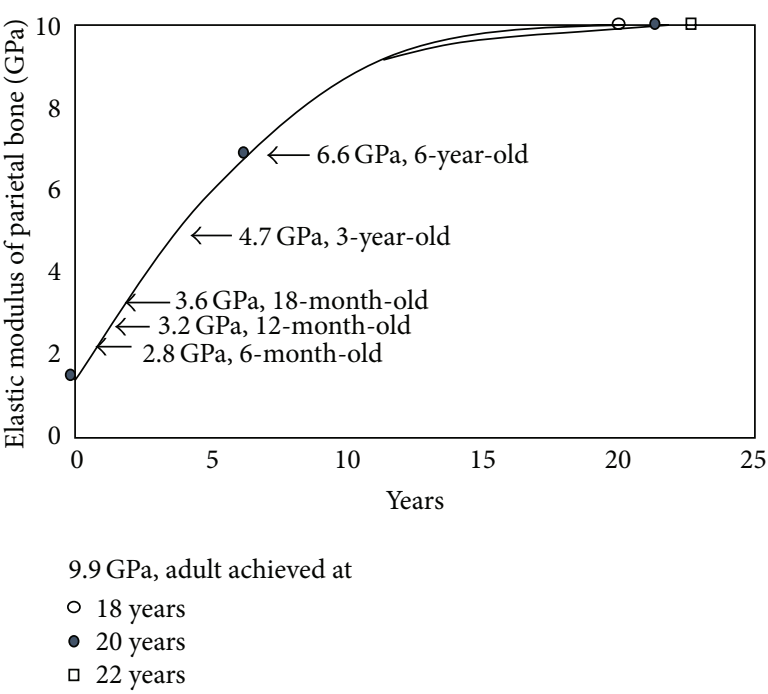

FIGURE 3: Skull Young's modulus as a function of age as established by Irwin and Mertz [18].

a function of donor age. Irwin and Mertz [18] established a curve based on the studies of McPherson and Kriewall [19] who presented elastic modulus for bending of parietal bone of six-year-old and new born children as 6.6 GPa and 2.5 GPa, respectively, while adult parietal bone elastic modulus was presented by Hubbard [20]. Figure 3 shows Irwin's curve.

Elastic modulus ratio is as follows:

$$
\lambda_{E}=\frac{E_{6 \mathrm{YO}}}{E_{9 \mathrm{YO}}} .
$$

The skull elastic modulus was found by interpolation from Irwin's curve (Figure 3): $E_{6 \mathrm{YO}}=6.6 \mathrm{GPa}$ and $E_{9 \mathrm{YO}}=7.4 \mathrm{GPa}$.

The length scaling factors are therefore equal to

$$
\begin{aligned}
& \lambda_{y}=\frac{\mathrm{HB}_{6 \mathrm{YO}}}{\mathrm{HB}_{9 \mathrm{YO}}}, \\
& \lambda_{x}=\frac{\mathrm{HH}_{6 \mathrm{YO}}}{\mathrm{HH}_{9 \mathrm{YO}}}, \\
& \lambda_{z}=\frac{\mathrm{HD}_{6 \mathrm{YO}}}{\mathrm{HD}_{9 \mathrm{YO}}} .
\end{aligned}
$$

Head acceleration scaling factor as derived by van Ratingen et al. [3] is

$$
\lambda_{a}=\sqrt{\frac{\lambda_{k}}{\lambda_{m}}},
$$

where $\lambda_{m}$ (see (8)) is the mass scaling factor and $\lambda_{k}$ is the stiffness scaling factor (see (2)). The characteristic length (CL) involves summing the head circumference (HC), head breadth, and head length (see (7)) for each size and taking their ratios [21]. Using this approach,

$$
\text { Characteristic length } \begin{aligned}
(\mathrm{CL}) & =\frac{\mathrm{CL}_{6 \mathrm{YO}}}{\mathrm{CL}_{9 \mathrm{YO}}}, \\
\mathrm{CL} & =\mathrm{HC}+\mathrm{HB}+\mathrm{HL} .
\end{aligned}
$$


TABLE 1: Summary of scaling factors.

\begin{tabular}{lcccc}
\hline Quantity & & 9 YO & $6 Y O$ & Scaling factors \\
\hline Mass & $\lambda_{m}$ & & & 0.9111 \\
Head breadth $(\mathrm{cm})$ & $\lambda_{y}$ & $14.2^{\mathrm{a}}$ & 13.9 & 0.9789 \\
Head height $(\mathrm{cm})$ & $\lambda_{x}$ & $19.0^{\mathrm{a}}$ & 18.4 & 0.9680 \\
Head length $(\mathrm{cm})$ & $\lambda_{z}$ & $18.6^{\mathrm{a}}$ & 18.1 & 0.9731 \\
Head circumference $(\mathrm{cm})$ & & $52.3^{\mathrm{a}}$ & 51.0 & \\
Elastic modulus $(\mathrm{GPa})$ & $\lambda_{E}$ & 7.4 & 6.6 & 0.8919 \\
Stiffness & $\lambda_{k}$ & & & 0.8685 \\
Acceleration & $\lambda_{a}$ & & & $\mathbf{0 . 9 7 6 3}$ \\
\hline
\end{tabular}

${ }^{\text {a }}$ Snyder et al. [22].

Assuming constant density,

$$
\lambda_{m}=(\mathrm{CL})^{3} \text {. }
$$

No specific dimensions of the $9 Y O$ cadaver head were given in Loyd's study; hence, anthropometric data of Snyder et al. [22] was applied to the nine-year-old child cadaver. Table 1 shows the scaling factors obtained using (1) to (8).

Six-year-old child head peak resultant acceleration was therefore obtained by scaling $9 \mathrm{YO}$ cadaver head peak resultant acceleration from Loyd's study for the three impact locations as shown in Table 2.

3.3. Material Properties Modification. A linear viscoelastic model was assigned to the head skin, while other head components were modelled as rigid materials. Linear viscoelastic model is Material Model 6 in LS-Dyna Software. It allows the modelling of viscoelastic behaviour of beams, shells, and solids [23]. Linear viscoelasticity is computed based on deviatoric stress tensor:

$$
S_{i j}=2 \int_{0}^{t} G(t-\tau) \frac{\partial \varepsilon_{i j}^{\prime}(\tau)}{\partial \tau} \partial \tau,
$$

where the shear relaxation behaviour is given by

$$
G(t)=G_{\infty}+\left(G_{0}-G_{\infty}\right) e^{-\beta t}
$$

where $G_{\infty}$ is long term shear modulus, $G_{0}$ is short term shear modulus, and $\beta$ is decay constant.

Since the head components are all rigid, the stiffness of the head skin is the parameter that affects head peak acceleration. Preliminary simulations were carried out using original $6 \mathrm{YO}$ hybrid III dummy head skin material properties in order to show the need of modifying skin viscoelastic parameters to mimic peak resultant acceleration of scaled $6 \mathrm{YO}$ cadaver head.

Figure 4 compares the peak resultant acceleration of original head model with scaled cadaver values. It can be seen that the original model is stiffer than scaled 6 YO cadaver data for all impact locations and drop heights. For both lower and higher drop heights, the peak resultant acceleration was about one-third or higher greater than scaled $6 \mathrm{YO}$ cadaver head peak acceleration. This is an indication of low biofidelity of the head model in evaluating injuries in all impact locations;

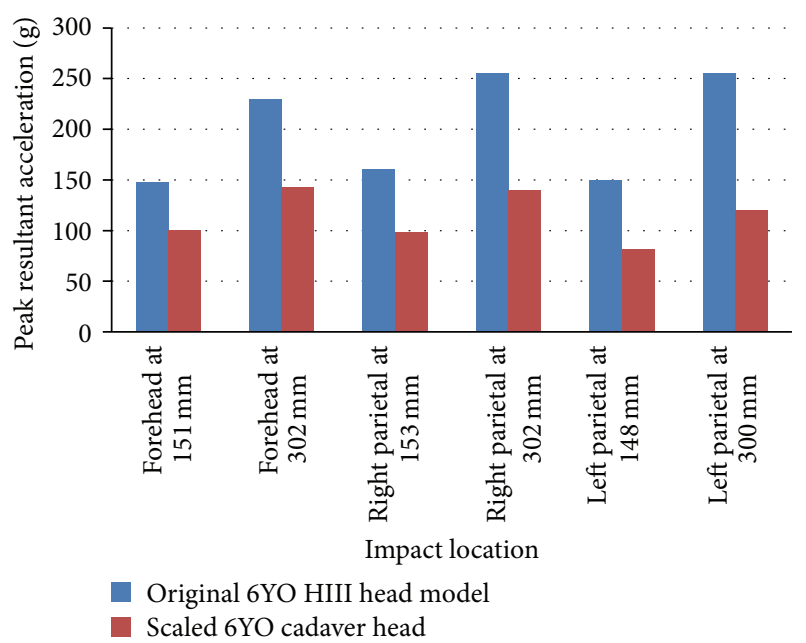

FIGURE 4: Comparison of $6 \mathrm{YO}$ hybrid III head model and $6 \mathrm{YO}$ scaled cadaver head peak resultant acceleration.

thus modifying the head response is necessary for better biofidelity.

The stiffness and viscosities of the skin were adjusted to ensure similar response with scaled cadaver experimental data in the three impact locations. Decreasing bulk modulus and short term and long term shear moduli determines the decreasing peak linear acceleration due to decrease in stiffness. These parameters were adjusted and optimized for peak resultant acceleration to match closely the scaled 6 YO child cadaver response. Table 3 presents the initial and modified material parameters.

3.4. Simulation Set-Up. The head model was isolated from dummy FE model and was oriented so that $z$-axis was at an angle of $28.5 \mathrm{deg}$. with horizontal impacting plate, while the midsagittal plane of the head was vertical. For right and left parietals' impact test, the midsagittal plane was at $35 \mathrm{deg}$. with impact surface from the top of the head. Figure 5 describes simulation set-up at the peak head acceleration for frontal impact.

Model impact velocities were applied to the head which were calculated based on the drop height between head and impacting plate. Surface to surface contact was defined between head and rigid plate with a friction coefficient of 0.2 and the hourglass energy was set to be $10 \%$ of the total energy. Simulations were carried out using finite element solver LS-DYNA version 971, and termination time was 10 milliseconds. Resultant acceleration results were processed using SAE $1000 \mathrm{~Hz}$ filter. Accelerometers are positioned in the child dummy head model as per the coordinate system specified through the Society of Automotive Engineers sign conventions recommendations [24].

\section{Simulation Results}

Peak resultant acceleration is a parameter used to quantify the head injury level associated with impacts. It is selected to validate the modified head model because of its relation to 
TABLE 2: Scaled 6YO experimental data.

\begin{tabular}{lcccc}
\hline Impact location & $\begin{array}{c}\text { Drop } \\
\text { height } \\
(\mathrm{mm})\end{array}$ & $\begin{array}{c}\text { 9YO child cadaver head } \\
\text { Peak resultant acceleration } \\
(\mathrm{g})\end{array}$ & $\begin{array}{c}\text { Acceleration scaling factor } \\
\text { Loyd (2011) }[2]\end{array}$ & $\begin{array}{c}\text { Scaled 6YO child head } \\
\text { Peak resultant acceleration } \\
(\mathrm{g})\end{array}$ \\
\hline Forehead & 151 & 102.6 & 0.9763 & 100.2 \\
Left parietal & 148 & 83.3 & 0.9763 & 81.3 \\
Right parietal & 153 & 100.2 & 0.9763 & 97.8 \\
Forehead & 302 & 146.3 & 0.9763 & 142.8 \\
Left parietal & 300 & 123.3 & 0.9763 & 120.4 \\
Right parietal & 302 & 142.5 & 0.9763 & 139.1 \\
\hline
\end{tabular}

TABLE 3: Head model material parameters.

\begin{tabular}{lccccc}
\hline $\begin{array}{l}\text { Viscoelastic } \\
\text { coefficients }\end{array}$ & $\begin{array}{c}\rho\left(\mathrm{Kg} / \mathrm{m}^{3}\right) \\
10^{-9}\end{array}$ & $\begin{array}{c}K \\
(\mathrm{MPa})\end{array}$ & $\begin{array}{c}G_{0} \\
(\mathrm{MPa})\end{array}$ & $\begin{array}{c}G_{1} \\
(\mathrm{MPa})\end{array}$ & $\begin{array}{c}\beta \\
(1 / \mathrm{Sec})\end{array}$ \\
\hline $\begin{array}{l}\text { Initial values } \\
\begin{array}{l}\text { Adjusted } \\
\text { values }\end{array}\end{array}$ & 1.2 & 23.6 & 8 & 5 & 250 \\
\hline
\end{tabular}

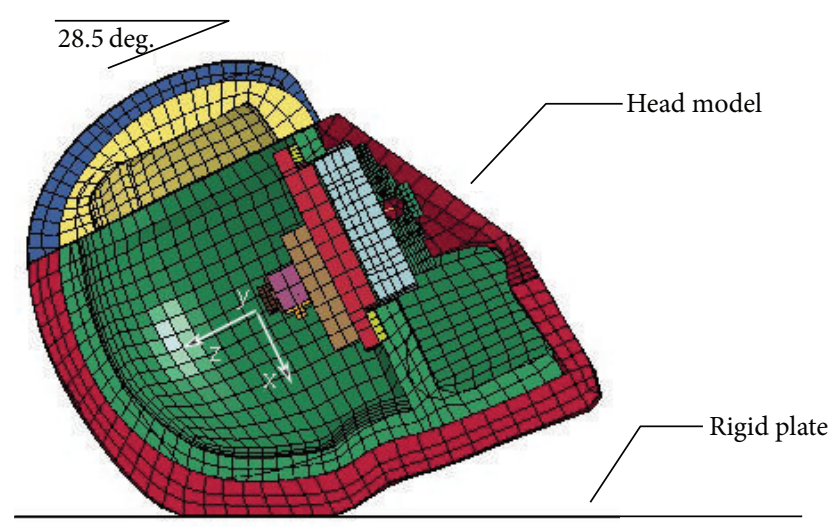

FIGURE 5: Simulation configuration for frontal impact.

head injury criteria (HIC) which is the standard metric used to assess injury risk and estimate when brain concussion and skull fracture will occur. Among other head biomechanical response parameters, it is the only one that is currently applied in ATD heads validation. Peak acceleration is measured by the accelerometer located at head CG. The result was plotted and compared with scaled experimental data for two drop heights as shown in Figures 6-8.

For all impact locations, the original hybrid III $6 \mathrm{YO}$ head model was stiff relative to the scaled $6 \mathrm{YO}$ peak resultant acceleration as indicated in Figure 4; hence the bulk modulus and long term and short term shear moduli values were varied to get optimum peak acceleration that will correlate well with scaled experimental data for three locations.

For frontal impact, the head response shows good agreement with scaled experimental data for $302 \mathrm{~mm}$ drop height with a difference of only $0.6 \%$ as shown in Figure 6 and Table 4. At lower drop height of $151 \mathrm{~mm}$ the head model

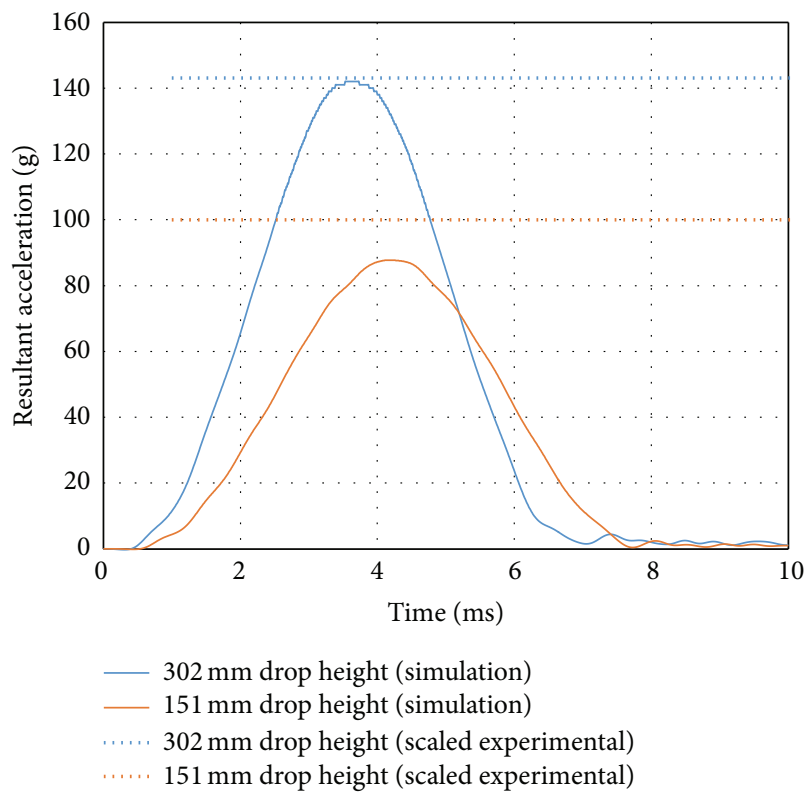

FIGURE 6: Resultant acceleration time history of modified head model for frontal impact. Dash lines represent scaled 6YO cadaver head peak acceleration.

was $12.3 \%$ less stiff than scaled data; thus the model was considered to be more biofidelic on dropping from higher height. Hybrid III 6 YO head peak acceleration is about 30\% higher than scaled 6YO cadaver as shown in Figure 4; thus a $12.3 \%$ difference for $151 \mathrm{~mm}$ drop height is an improved biofidelity.

Right parietal appeared to have good biofidelity as its peak resultant acceleration value correlates well with scaled experimental data with a difference of $4.4 \%$ for $153 \mathrm{~mm}$ drop height. It was however found to be stiffer than scaled experimental data by $16.4 \%$ for $302 \mathrm{~mm}$ drop height as indicated in Table 4 . This shows the ability of the modified head model to measure right parietal impacts especially at lower drop heights. The head model response was fairly biofidelic at $302 \mathrm{~mm}$ drop height, considering the original head model response which was about $83 \%$ stiffer than scaled experimental data as seen in Figure 4; hence, significant reduction in stiffness of about $67 \%$ indicates improved biofidelity. Figure 7 shows 
TABLE 4: Summary of simulation results.

\begin{tabular}{lccccc}
\hline Impact location & $\begin{array}{c}\text { Drop height } \\
(\mathrm{mm})\end{array}$ & $\begin{array}{c}\text { Impact velocity } \\
\mathrm{mm} / \mathrm{Sec}\end{array}$ & $\begin{array}{c}\text { Scaled experimental results } \\
(\mathrm{g})\end{array}$ & $\begin{array}{c}\text { Simulation results } \\
(\mathrm{g})\end{array}$ & $\begin{array}{c}\text { Difference } \\
(\%)\end{array}$ \\
\hline Forehead & 151 & 1721 & 100.2 & 87.8 & 12.3 \\
Left parietal & 148 & 1704 & 81.3 & 97.0 & 19.3 \\
Right parietal & 153 & 1733 & 97.8 & 102.1 & 141.9 \\
Forehead & 302 & 2434 & 142.8 & 157.7 & 0.6 \\
Left parietal & 300 & 2426 & 120.4 & 161.9 & 30 \\
Right parietal & 302 & 2434 & 139.1 & 16.4 \\
\hline
\end{tabular}

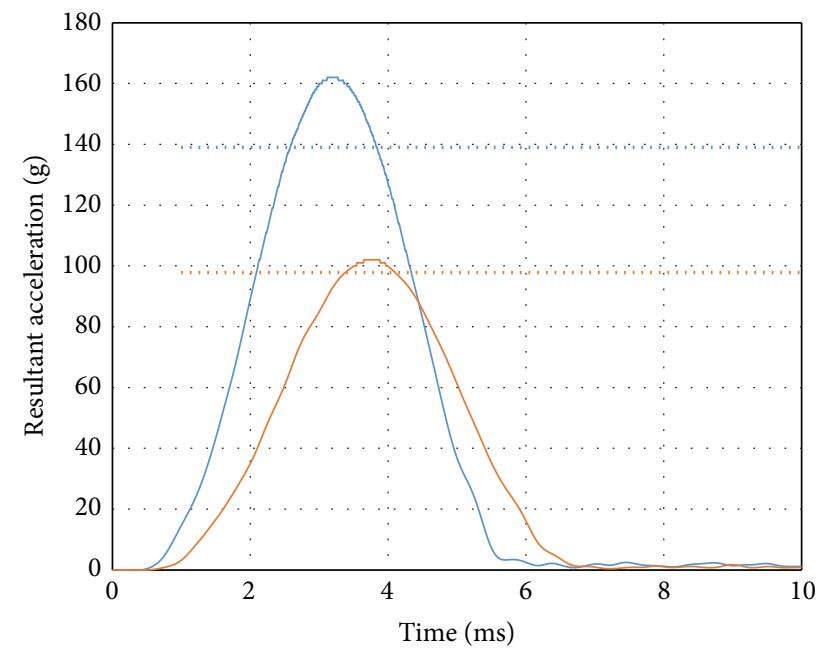

$-302 \mathrm{~mm}$ drop height (simulation)
$\ldots \ldots 3 \mathrm{~mm}$ drop height (simulation)
$\ldots \ldots 302 \mathrm{~mm}$ drop height (scaled experimental)
$\ldots \ldots 153 \mathrm{~mm}$ drop height (scaled experimental)

FIgURE 7: Resultant acceleration time history of modified head model for right parietal. Dash lines represent scaled 6 YO cadaver head peak acceleration.

the simulation results compared with scaled experimental data.

Left parietal, however, shows higher peak impact acceleration values than the scaled experimental results, which indicates its low biofidelity response compared to other impact locations as shown in Figure 8. The level of validation was very low with a difference of $30 \%$ for $300 \mathrm{~mm}$ drop height. The head model is more biofidelic for the drop height of $148 \mathrm{~mm}$, where the difference of peak acceleration between the model and scaled experimental data is $19.3 \%$ as seen in Table 4 . It is therefore suggested that the head model must be used cautiously for higher heights. It is worth noting that left and right parietal locations of the head model are symmetrical and this can be confirmed from the simulation results for both original and modified head models (Figure 4). The differences in peak acceleration values between right and left parietals could be attributed to small difference in drop height from which impact velocities were calculated. The scaled $6 \mathrm{YO}$ child cadaver peak resultant acceleration values for right and left parietals show no symmetry as the difference in peak

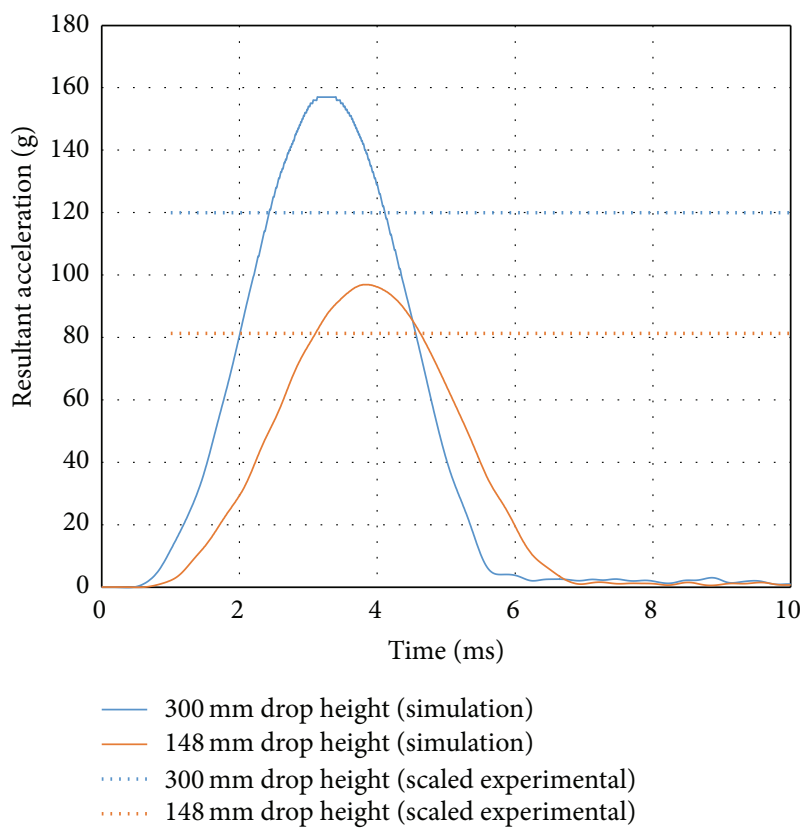

FIGURE 8: Resultant acceleration time history of modified head model for left parietal. Dash lines represent scaled 6YO cadaver head peak acceleration.

resultant acceleration was high between the two locations as seen in Table 4. This is because in human head each impact location has different skull thickness and hence locations with high thickness would have high impact acceleration values. Despite higher peak acceleration noticed in left parietal, an improvement has been achieved considering the disparity in percentage difference between original hybrid III 6YO and scaled $6 \mathrm{YO}$ cadaver peak resultant acceleration values which is reduced by $50 \%$ and $82 \%$ for $148 \mathrm{~mm}$ and $300 \mathrm{~mm}$ drop heights, respectively.

The peak acceleration value differences noticed in parietal locations can be attributed to viscoelastic material parameters optimization limitations with respect to impact locations and also due to the fact that the head model was designed symmetrically and for frontal impact assessment only. The symmetrical nature of the head model made it difficult to modify the material parameters in the parietal locations such that the peak resultant acceleration values will be close to scaled experimental data. Despite all these limitations, some level of biofidelity has been achieved. Better biofidelity could 
be obtained by validating the head model using more cadaver head samples and by modifying the head geometry.

\section{Conclusions}

The purpose of this study was to improve the biofidelity of the original hybrid III 6YO dummy head model for frontal impact and to extend its application to right and left parietal locations. To fulfil this purpose, Mertz scaling equations were applied to scale $9 \mathrm{YO}$ cadaver head response to $6 \mathrm{YO}$ child head peak resultant acceleration. Original 6YO hybrid III dummy head was first compared with scaled $6 \mathrm{YO}$ peak resultant acceleration for frontal, right, and left parietal locations from which it was shown to have lower biofidelity. The head model skin viscoelastic material properties were modified by adjusting material parameters for the peak acceleration to match as closely as possible with scaled 6YO child cadaver head response data. Improvement of biofidelity has been achieved in frontal and right parietal impact locations, while left parietal shows lower biofidelity. The fair biofidelic behaviour of the head model is related to the fact that the head model was initially designed symmetrically and for frontal impact assessment only. In the future work, we hope to overcome the low biofidelity of the head model by modifying the geometry of the left and right parietals for the stiffness response in these locations to correlate with scaled cadaver data. The amended head model is considered to be more biofidelic than the current hybrid III 6YO dummy head model in all the three impact locations. It could therefore be used in developing hybrid III $6 \mathrm{YO}$ side impact dummy as it can be applied to right and left parietals' impact assessment.

\section{Conflict of Interests}

The authors declare that there is no conflict of interests regarding the publication of this paper.

\section{Acknowledgments}

The authors wish to thank Universiti Putra Malaysia for the facilities and Bayero University, Kano, Nigeria, for the financial support given to the first author. In addition, this work was also supported by Fundamental Research Grant Scheme with Reference no. FRGS/2/2013/TK01/UPM/01/1, vot 5524355, Ministry of Education (MOE), Malaysia, and was carried out in Universiti Putra Malaysia (UPM). The authors therefore would like to record their thanks to the MOE and UPM for the support.

\section{References}

[1] A. M. Loyd, R. W. Nightingale, Y. Song et al., "Impact properties of adult and ATD heads," in Proceedings of the International Research Council on the Biomechanics of Injury (IRCOBI '12), vol. 507, pp. 552-564, Dublin, Ireland, September 2012.

[2] A. M. Loyd, Studies of the human head from neonate to adult: an inertial, geometrical and structural analysis with comparisons to the ATD head [P.hD. Dissertation], Department of Biomedical Engineering, Duke University, Durham, NC, USA, 2011.
[3] M. R. van Ratingen, D. Twisk, M. Schrooten, M. C. Beusenberg, A. Barnes, and G. Platten, "Biomechanically based design and performance targets for a 3-year old child crash dummy for frontal and side impact," SAE Technical Paper 973316, SAE, 1997.

[4] First Technology Safety System (FTSS), LS-DYNA Model of the Hybrid III 3-Year Old Child Dummy User Manual, Version 4.0, First Technology Safety System (FTSS), Plymouth, Mich, USA, 2008.

[5] LSTC, LSTC Hybrid III 6 Year Old Finite Element Model Documentation, LSTC, 2013.

[6] V. R. Hodgson and L. M. Thomas, "Comparison of head acceleration injury indices in cadaver skull fracture," SAE Technical Paper 710854, 1971.

[7] F. J. Lopez-Valdes, J. Forman, R. Kent, O. Bostrom, and M. Segui-Gomez, "A comparison between a child-size PMHS and the Hybrid III 6 YO in a sled frontal impact," Annals of Advances in Automotive Medicine, vol. 53, pp. 237-246, 2009.

[8] J. Wu, L. Cao, M. P. Reed, and J. Hu, "A simulation study of spine biofidelity in the Hybrid-III 6-year-old ATD," Traffic Injury Prevention, vol. 14, no. 4, pp. 397-404, 2013.

[9] J. Hu, K. D. Klinich, M. P. Reed, M. Kokkolaras, and J. D. Rupp, "Development and validation of a modified Hybrid-III six-yearold dummy model for simulating submarining in motor-vehicle crashes," Medical Engineering and Physics, vol. 34, no. 5, pp. 541551, 2012.

[10] K. Weber, "Crash protection for child passengers: a review of the best practice," UMTRI Research Review, vol. 31, no. 3, pp. 1-28, 2000.

[11] C. Maurath, S. Guha, D. Bhalsod et al., "Overview of LSTC's LS-DYNA anthropomorphic models," in Proceedings of the 11th International LS-DYNA Conference, pp. 41-52, Dearborn, Mich, USA, June 2010.

[12] K. Mizuno, K. Iwata, T. Deguchi, T. Ikami, and M. Kubota, "Development of a three-year-old child FE model," Traffic Injury Prevention, vol. 6, no. 4, pp. 361-371, 2005.

[13] T. Koizumi, N. Tsujiuchi, and Y. Uchida, "Impact injury rating of child FE human model for 3-year-old," in Proceedings of the IMAC-XXIII: Conference and Exposition on Structural Dynamics, Orlando, Fla, USA, January-February 2005.

[14] B. Been, R. Meijer, F. Bermond et al., "WorldSID small female side impact dummy specifications and prototype evaluation," in Proceedings of the 20th Enhanced Safety of Vehicles Conference (ESV '07), Lyon, France, 2007.

[15] J. Ash, Y. Abdelilah, J. Crandall, D. Parent, C. Sherwood, and D. Kallieris, "Comparison of anthropomorphic test dummies with a pediatric cadaver restrained by a three-point belt in frontal sled tests," in Proceedings of the 21st International Technical Conference on the Enhanced Safety of Vehicles (ESV'09), pp. 1-14, Stuttgart, Germany, June 2009.

[16] R. Meijer, R. Wisgerhof, J. Wismans, and B. Been, "Scaling headneck response data and derivation of 5 th percentile female sideimpact dummy head-neck response requirements in NBDL test conditions," International Journal of Crashworthiness, vol. 15, no. 1, p. 115, 2010.

[17] H. J. Mertz, A. L. Irwin, J. W. Melvin, R. L. Stanaker, and M. S. Beebe, "Size, weight and biomechanical impact response requirements for adult size small female and large male dummies," SAE Technical Paper 890756, 1989.

[18] A. Irwin and H. J. Mertz, "Biomechanical basis for the CRABI and Hybrid III child dummies," SAE Technical Paper 973317, 1997. 
[19] G. K. McPherson and T. J. Kriewall, "The elastic modulus of fetal cranial bone: a first step towards an understanding of the biomechanics of fetal head molding," Journal of Biomechanics, vol. 13, no. 1, pp. 9-16, 1980.

[20] R. P. Hubbard, "Flexure of layered cranial bone," Journal of Biomechanics, vol. 4, no. 4, pp. 251-263, 1971.

[21] K. D. Klinich, R. A. Saul, G. Auguste, S. Backaitis, and M. Kleinberger, Techniques for Developing Child Dummy Protection Reference Values, National Highway Traffic Safety Administration, 1996.

[22] R. G. Snyder, L. W. Schneider, C. L. Owings, H. M. Reynolds, H. Golomb, and A. Schork, "Anthopometry of infants, children and youth to age 18 for product safety design," Measurement Final Report, 1977.

[23] J. O. Hallquist, DYNA Theory Manual, Livermore Software Technology Corporation (LSTC), 2006.

[24] LS-DYNA, LS-DYNA Model of the Hybrid III 3-Year Old Child Dummy User Manual 4.0, LS-DYNA Model Version, LS-DYNA, 2008. 


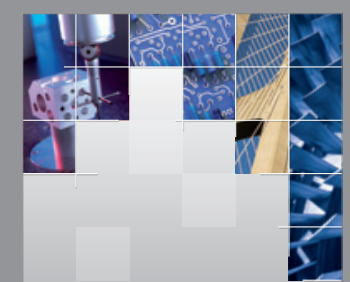

\section{Enfincering}
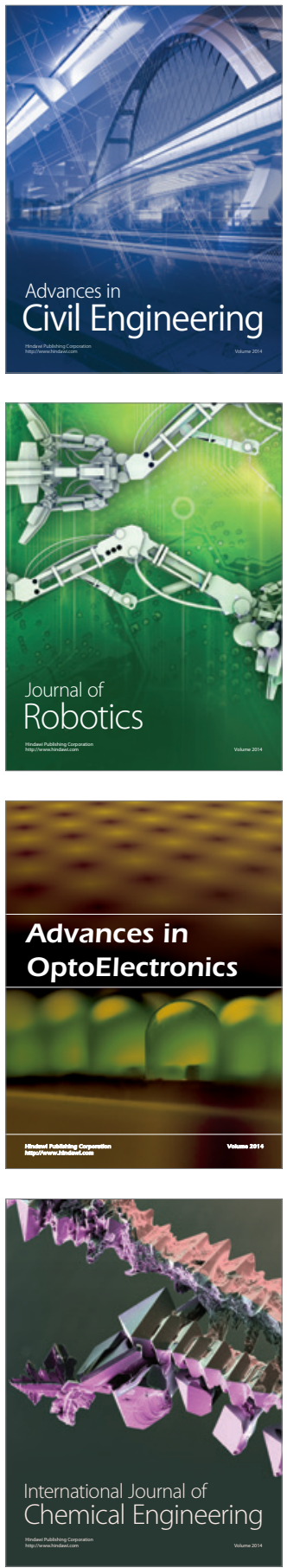

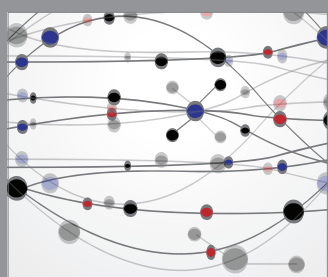

The Scientific World Journal

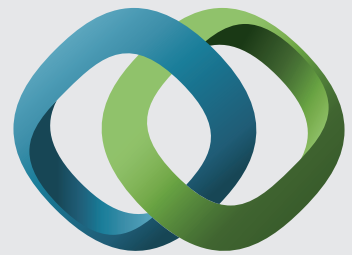

\section{Hindawi}

Submit your manuscripts at

http://www.hindawi.com
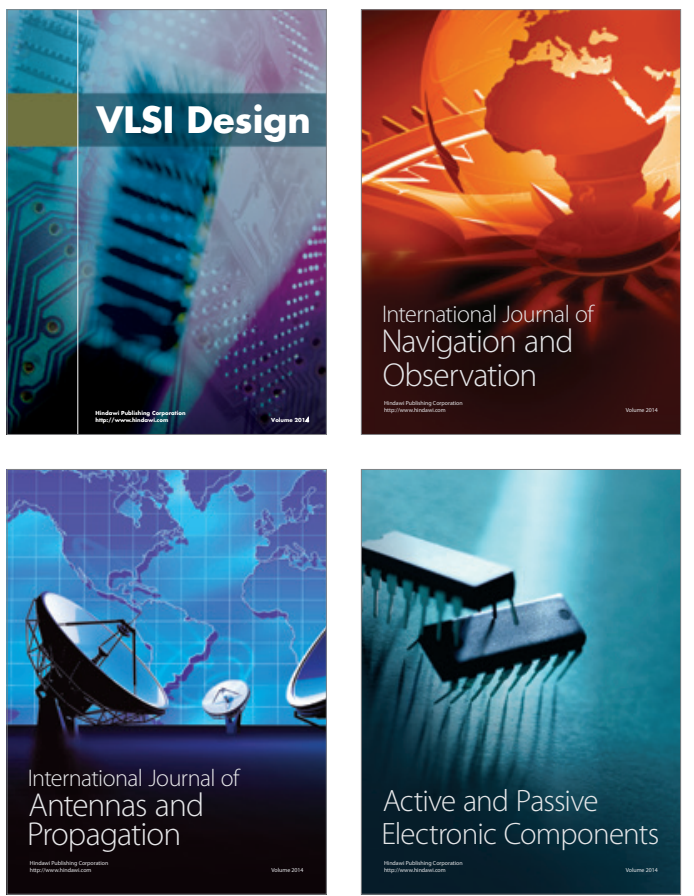
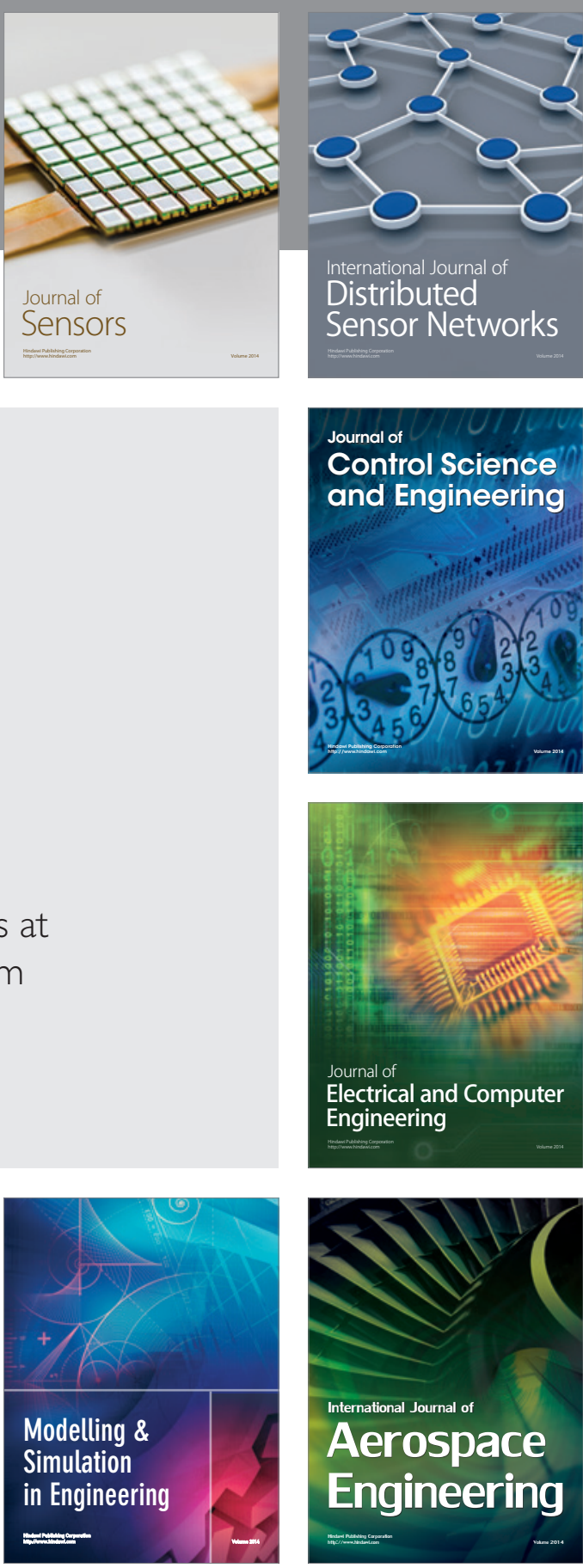

International Journal of

Distributed

Sensor Networks

Journal of

Control Science

and Engineering
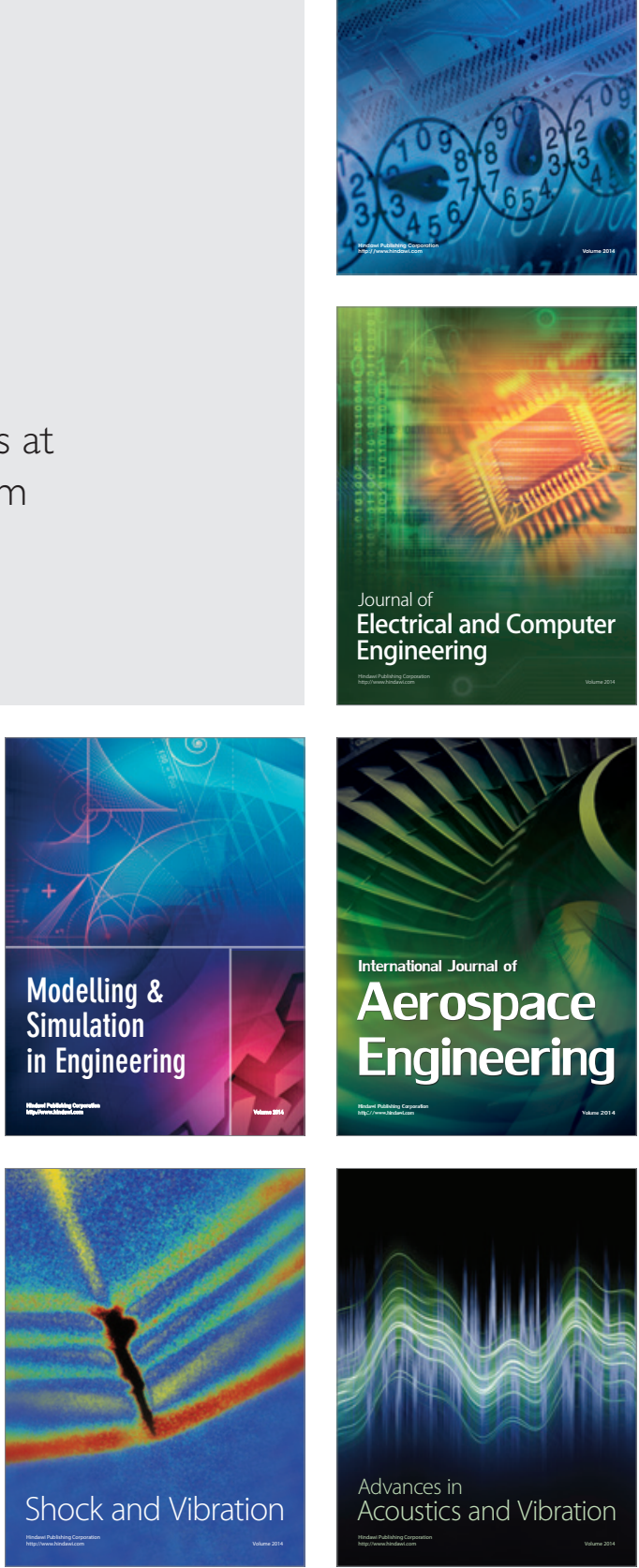